OnLine Journal of Earth Sciences 4 (1): 1-5, 2010

ISSN: 1991-7708

(C) Medwell Journals, 2010

\title{
Mathematical Modelling of N-Stage Rocket
}

\author{
O.O. Adewole and A.A. Adetoyinbo \\ Department of Physics, Adeyemi College of Education, P.M.B. 520, Ondo, Ondo State, Nigeria
}

\section{INTRODUCTION}

The planet Earth on which man lives is one of the most difficult to observe. This limitation arises from man's limited visibility on the earth surface and his relative isolation in the spot on the earth in which he finds himself. To facilitate observations of the planet earth and exploring outer surface man has been inspired to build a vehicle and as a sounding rocket to enhance the task. A rocket is a transport vehicle that carries astronauts and satellites up into space. The propulsion is created by burning so gaseous fuel such as oxygen and nitrogen. The gas is compressed and pushed out through the booster. This causes a reaction and forces the thrust to move the rocket upwards (Young annd Roger, 1965; Sutton, 1986), this is a consequence of Newton's 3rd law of motion which states for every motion, there is a reaction that is equal in magnitude but opposite in direction to the action. Rockets have been used extensively over the years. Majorly, they have been used in wars. In world war II, the Everman big rockets V-2 was used against the Allies and after the world war II, scientists conducted experiment on the German. V-2's which were used at high altitude for research (Larson and Wertz, 1992). The US armed forces during the 1950's developed rockets including Jupiter and Perishing. The Jupiter had a range of about 1,600 miles and the perishing has 450 miles. The US Navy conducted the just successful land of a Polaris, underwater missile in 1960. After Apollo, the team at Marshall tackled designing a revolutionary national space transportation system which came to be known simply as The Space Shuttle. The space shuttle main engines are among the most powerful, most sophisticated derives ever invented. The thrust to $<7,000$ pounds but jets out the power equivalent of several into orbit having undergone many design changes. It major components at the space shuttle are 2 Solid Rocket Boosters (SRB) which is critique for launch, External fuel Tank (ET) which caries fuel for the launch and orbiter which caries astronauts and payload.

The challenge disaster has been the busiest in the history of marshall space flight center. Rocket propulsion experts devised a number of modifications to the solid rocket motor design to remedy the fault that led to the disaster. The disaster was a strong impetus for marshall and other NASA installations to address other shunter related rockets concerns having designed a vigorous test program to ascertain the problems in the challenges disaster has been solved.

\section{MATERIALS AND METHODS}

The researchers have been able to present a mathematical formulation for the model of an n-stage rocket to put a satellite in orbit considering the effect of gravity. Also a computer program may be written to calculate the mass of an n-stage rocket to orbit a 1 ton satellite for $\mathrm{V}, \mathrm{u}$ and $\lambda$ assumed moving:

$$
\frac{m_{0}}{m_{p}}=\left(\frac{1-\lambda}{p-\lambda}\right)^{5}
$$

and,

$$
\mathrm{p}=\exp \left(\frac{-\mathrm{V}+\mathrm{gt}_{\mathrm{f}}}{\mathrm{un}}\right)
$$

Theory: Rockets like other forms of propulsion expend energy to produce a thrust force via an exchange of momentum with some reaction mass in accordance with Newton's third law of motion.

Unlike other forms of propulsion, rockets carry their reaction mass with them i.e., self-contained and are therefore independent on their environment. Other forms of propulsion depend on their environment to provide the reaction mass for example cars use the ground, air planes use the air and boats. Use the water and sail boats used the wind. The most familiar rockets are chemical rockets in which reaction mass are the fuel and oxidized, the propellant is inertia mass (Hill and Perterson, 1990).

The rocket principle can be analysed by the basic Newton's lacks of motion. According to Newton's second law, the thrust for a is equal to the rate of change of momentum of the ejected matter which depends on both how much and how task propellants are used (mass flow rate) and the propellants speed when it

Corresponding Author: O.O. Adewole, Department of Physics, Adeyemi College of Education, P.M.B. 520, Ondo, Ondo State, Nigeria 
leaves the rocket (effective exhaust velocity). Like other forms of transportation, rockets consist of the same basic elements such as a structure providing framework, propulsion system providing the force for motion, energy source for powering the vehicle systems, guidance system for direction control and most important the payload such as passengers (astronauts), scientific instruments which is the reason of constructing the vehicle. Rocket performance depends on thrusts, specific impulse and mass ratio.

Thrust (T): Thrust is the amount of force an engine produces on the earth and the exhaust stream leaving the rocket, conservation of momentum. The mission profile determines the acceleration and thrust required. Typically, landing from the earth resulted a thrust to weight ratio of 1.5-1.75. The thrust of the rocket at any given time is $\mathrm{F}=\mathrm{m}^{*} \mathrm{Ve}$ where $\mathrm{m}^{*}$ is mass flow rate for a rocket and not constant, ve is the exhaust validity.

Specific impulse: It is measure propellant efficiency and numerically is the thrust produced divided by the weight of propellant consumed per second i.e.,

$$
I_{s p}=\frac{F}{m^{*} g}
$$

Mass ratio $\left(\mathbf{m}_{\mathrm{p}}\right)$ : Since the rocket engine is continually consuming propellants, the rocket's mass if increasing with time and if the thrust remains constant the rockets acceleration increases reaching its highest value at cut-off if mass ratio is the expression relating the propellant mass to the rocket mass, the higher the mass ratio, the higher the final speed of the rocket.

Staging: The only practical way of launching satellites is with chemical engines (e.g., rockets). The factors listed specific impulse and mass ratio limit the chemical system performance (Ball and Osborne, 1967). The only solution to this problem is to mount one or more rockets on top of one another and to fire them in succession at the moment of the previous stage burns out. For instance, to reach the moon, a body must attain a velocity of $35,000 \mathrm{ft}$. sec ${ }^{-1}$. No practical rocket of one stage can reach the critical velocities for satellites or space probes. Thus, if each stage provides about $9,000 \mathrm{ft}$. $\mathrm{sec}^{-1}$ velocity when fires it will take three stages or four stages of hit the moon. With staging, the launch size and weight of the vehicle required for a specific mission is reduced and aid in achieving the high velocity necessary for specific missions.

Multi stage rocket allows improved payload capability for rockets with high $\Delta V$ requirements such as launch velocities and inter planetary space crafts. The same rocket equation describes a multi stage and statestage rocket performance but it must be applied on a stage-by-stage basis .

The motion of the satellite: We can assume the earth is fixed in space, spherical and has a spherically symmetric density distribution. The motion of the satellite in orbit is due to gravity from the earth, the satellite moves along a target to the earth's surface assuming no force acts on it at that point. The gravitational force on a satellite of mass, $\mathrm{m}$ at a distance $\mathrm{r}$ from the centre of the earth is given by $\mathrm{F}=\mathrm{G}^{1} \mathrm{~m} / \mathrm{r}^{2}$ (Newton's Law of universal gravitation). The force exerted by gravity on a mass $\mathrm{M}$ at a distance $\mathrm{r}$ from the centre of the earth is $\mathrm{Km} / \mathrm{r}^{2}$ ( $\mathrm{K}=$ constant). For earth of radius $\mathrm{R}(\mathrm{r}>\mathrm{R})$, Newton's 2 nd law of motion gives:

$$
\mathrm{mg}=\frac{\mathrm{Km}}{\mathrm{r}^{2}} \Rightarrow \mathrm{K}=\mathrm{gR}^{2}
$$

Thus; $\mathrm{F}=\mathrm{Km} / \mathrm{r}^{2}=\mathrm{MgR}^{2} / \mathrm{r}^{2}, \mathrm{~m}$ is the mass of the particle and $g$ is the acceleration due to gravity. Suppose the satellite is moving in an orbit $600 \mathrm{~km}$ above the surface of the earth, assuming $\mathrm{g}=9.8 / \mathrm{m} / \mathrm{sec}^{2}, \mathrm{R}=6,400 \mathrm{~km}$, $\mathrm{v}$ can be found as follows:

$$
\begin{gathered}
\frac{\mathrm{mgR}^{2}}{\mathrm{r}^{2}}=\frac{\mathrm{mV}^{2}}{\mathrm{r}} \Rightarrow \mathrm{V}=\mathrm{R}(\mathrm{g} / \mathrm{r})^{1 / 2} \\
\mathrm{~V}=6400 \times 10^{3}\left(\frac{9.81}{600 \times 10^{3}}\right)^{1 / 2}=7.6 \mathrm{~km} \mathrm{sec}^{-1}
\end{gathered}
$$

Force exerted by a rocket engine: Considering a simple model of a rocket engine and a container for the fuel, the resulting gases expelled from the end of the rocket when the fuel is burned in the engine results to the burning and streaming of gases which exert a force and thrust on the rocket (Newton's 3rd law of motion):

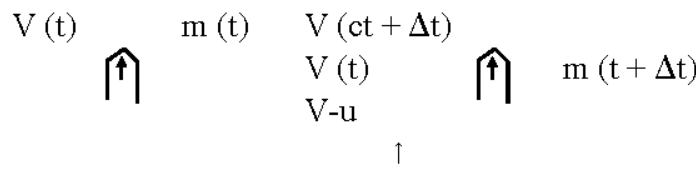

Suppose at time $t$, the rocket has a mass $m(t)$ and Velocity $\mathrm{V}(\mathrm{t})$. At time $\mathrm{t}+\Delta \mathrm{t}$, the rocket has a mass $\mathrm{m}(\mathrm{t}+\Delta \mathrm{t})$. Applying the principle of conservation of momentum;

$$
\mathrm{m}(\mathrm{t}) \mathrm{V}(\mathrm{t})=\mathrm{m}(\mathrm{t}+\Delta \mathrm{t}) \mathrm{V}(\mathrm{t}+\Delta \mathrm{t})-\left(\frac{\mathrm{dm}}{\mathrm{dt}} \Delta \mathrm{t}\right)(\mathrm{V}(\mathrm{t})-\mathrm{u})
$$


It can be shown that $\mathrm{mdv} / \mathrm{dt}=-\mathrm{udm} / \mathrm{dt}$ which obviously depends on the rate at which fuel is consumed multiplied by the velocity of the ejected gases relative to the rocket. $\mathrm{Mdv} / \mathrm{dt}$ represents the internal force on the rocket. With an external force; Fext = mg:

$$
\frac{\mathrm{mdv}}{\mathrm{dt}}+\frac{\mathrm{udm}}{\mathrm{dt}}=-\mathrm{mg}
$$

and can be shown from $\mathrm{Mdv} / \mathrm{dt}=\mathrm{udm} / \mathrm{dt}-\mathrm{mg}$ that:

$$
\mathrm{V}=\mathrm{u}\left(\mathrm{n}\left(\frac{\mathrm{m}_{\mathrm{o}}}{\mathrm{m}(\mathrm{t})}\right)\right)-\mathrm{gt}_{\mathrm{f}} \quad \text { for } \mathrm{V}_{\mathrm{o}}=\mathrm{t}_{\mathrm{o}}=0
$$

Where:

$\mathrm{m}_{0}=\quad$ The initial mass of the rocket

$\mathrm{V}_{0}=$ The velocity at time $\mathrm{t}=0, \mathrm{t}_{\mathrm{f}}=\mathrm{t}-\mathrm{t}_{\mathrm{o}}$

Obviously, the final velocity of the rocket depends on the velocity $u$ of the expelled gases relative to the rocket, the mass ratio of the rocket $\mathrm{s}$, stem, acceleration due to gravity and the burn time $t$ which depends on the attitude.

The mass of a rocket-satellite system: Considering the idealized situation i.e., to get the ideal performance, he assume that between times $t$ and $t+\Delta t$, a fraction $\lambda$ of the change in mass is structural mass which is simply thrown away and a fraction $(1-\lambda)$ is burned and expelled as gas at velocity $u$. Thus, the mass ratio is given by;

$$
\frac{\mathrm{m}_{0}}{\mathrm{~m}_{\mathrm{p}}}=\exp \left(\frac{\mathrm{V}+\mathrm{gt}_{\mathrm{f}}}{\mathrm{u}(1-\lambda)}\right)
$$

$\mathrm{m}_{0}=$ The initial mass

$\mathrm{m}_{\mathrm{p}}=$ The payload

Practical realization of the ideal performance: The initial mass of the rocket is given by:

$$
\mathrm{m}_{\mathrm{o}}=\mathrm{m}_{\mathrm{p}}+\mathrm{m}_{1}+\mathrm{m}_{2}+\mathrm{m}_{3}
$$

Letting $\mathrm{m}_{\mathrm{i}}=$ weight of (fuel + structure) in the ith stage and suppose that $\lambda \mathrm{m}$ of this is structure and $(1-\lambda) \mathrm{m}_{\mathrm{i}}$ is fuel where we assume for simplicity that $\lambda$ is constant for all stages and also the exhaust velocity, $\mathrm{u}$ is constant. From :

$$
\frac{\mathrm{mdv}}{\mathrm{dt}}+\frac{\mathrm{udm}}{\mathrm{dt}}=-\mathrm{mg}
$$

It can be shown that:

$$
\begin{aligned}
& \mathrm{v}-\mathrm{v}_{\mathrm{o}}=\mathrm{u}\left(\mathrm{I}\left(\mathrm{nm}-\mathrm{Inm}_{\mathrm{o}}\right)-\mathrm{g}\left(\mathrm{t}-\mathrm{t}_{0}\right), \mathrm{t}_{\mathrm{o}}=\mathrm{u}_{\mathrm{o}}=0\right. \\
& \mathrm{V}=\mathrm{uIn}\left(\frac{\mathrm{m}_{\mathrm{o}}}{\mathrm{m}(\mathrm{t})}\right)-\mathrm{gt} \\
& \frac{\mathrm{m}_{\mathrm{o}}}{\mathrm{m}}=\exp \left(\frac{\mathrm{v}+\mathrm{gt}}{\mathrm{u}}\right)
\end{aligned}
$$

After 1st stage, fuel is burnt:

$$
\begin{gathered}
\mathrm{m}=\mathrm{m}_{\mathrm{p}}+\lambda \mathrm{m}_{1}+\mathrm{m}_{2}+\mathrm{m}_{3}, \mathrm{t}=\mathrm{t}_{1} \\
\mathrm{~V}_{1}=\mathrm{uIn}\left(\frac{\mathrm{m}_{\mathrm{o}}}{\mathrm{m}_{\mathrm{p}}+\lambda \mathrm{m}_{1}+\mathrm{m}_{2}+\mathrm{m}_{3}}\right)-\mathrm{gtp}
\end{gathered}
$$

After 2nd stage, fuel is burnt:

$$
\begin{gathered}
\mathrm{m}=\mathrm{m}_{\mathrm{p}}+\lambda \mathrm{m}_{2} \mathrm{~m}_{3} ; \mathrm{t}=\mathrm{t}_{2} \\
\mathrm{~V}_{2}=\mathrm{V}_{1}+\mathrm{uIn}\left(\frac{\mathrm{m}_{\mathrm{p}}+\mathrm{m}_{2}+\mathrm{m}_{3}}{\mathrm{~m}_{\mathrm{p}}+\lambda \mathrm{m}_{2}+\mathrm{m}_{3}}\right)-\mathrm{gtp}_{2}
\end{gathered}
$$

After 3rd stage, fuel is burnt:

$$
\begin{gathered}
\mathrm{m}=\mathrm{m}=+\lambda \mathrm{m}_{3}, \mathrm{t}=\mathrm{t}_{3} \\
\mathrm{~V}=\mathrm{V}_{2}+\mathrm{uIn}\left(\frac{\mathrm{m}_{0}+\mathrm{m}_{2}}{\mathrm{~m}_{\mathrm{p}}+\lambda \mathrm{m}_{3}}\right)-\mathrm{gt}_{2}
\end{gathered}
$$

Hence,

$$
\mathrm{t}_{1}+\mathrm{t}_{2}+\mathrm{t}_{3}=\mathrm{t}_{\mathrm{f}}
$$

with,

$$
t_{1}=t_{2}=t_{3}=t^{1}=3 t^{1}=t_{f} \Rightarrow t^{1}=1 / 3 t_{f}
$$

$$
\begin{aligned}
& \mathrm{V}_{1}+\mathrm{V}_{2}+\mathrm{V}_{3}=\mathrm{uIn}\left(\frac{\mathrm{m}_{0}}{\mathrm{~m}_{\mathrm{p}}+\lambda \mathrm{m}_{1}+\mathrm{m}_{2}+\mathrm{m}_{3}}\right)-\frac{1}{3} \mathrm{gt}_{\mathrm{f}}+ \\
& \mathrm{V}_{1}+\mathrm{uIn}\left(\frac{\mathrm{m}_{\mathrm{p}}+\mathrm{m}_{2}+\mathrm{m}_{3}}{\mathrm{~m}_{\mathrm{p}}+\lambda \mathrm{m}_{2}+\mathrm{m}_{3}}\right)-\frac{1}{3} \mathrm{gt}_{\mathrm{f}}+ \\
& \mathrm{V}_{2}+\operatorname{uIn}\left(\frac{\mathrm{m}_{\mathrm{p}}+\mathrm{m}_{3}}{\mathrm{~m}_{\mathrm{p}}+\mathrm{m}_{3}}\right)-\frac{1}{3} \mathrm{gt}_{\mathrm{f}}
\end{aligned}
$$

It can be shown that:

$$
\frac{m_{0}}{m_{p}}=\left(\frac{1-\lambda}{P-\lambda}\right)^{n}
$$


OnLine J. Earth Sci., 4 (1): 1-5, 2010

Where:

$$
\mathrm{p}=\exp \left(\frac{-\mathrm{V}+\mathrm{gt}_{\mathrm{f}}}{\mathrm{nu}}\right)
$$

and $\mathrm{n}$ is the number of stages.

\section{RESULTS AND DISCUSSION}

The researchers intend to investigate whether it would be of economic gain or any benefit to build a 2 or 4 stage rocket or a 3 stage rocket. The optimum ratio of $\mathrm{m}_{\mathrm{o}} / \mathrm{m}_{\mathrm{p}}$ for an n-stage rocket is;

$$
\frac{\mathrm{m}_{0}}{\mathrm{~m}_{\mathrm{p}}}=\left(\frac{1-\lambda}{\mathrm{P}-\lambda}\right)^{\mathrm{n}}
$$

Where;

$$
\mathrm{P}=\exp \left(\frac{-\mathrm{V}+\mathrm{gt}_{\mathrm{f}}}{\mathrm{nu}}\right)
$$

For $\mathrm{n}=1$,

$$
\begin{gathered}
\frac{\mathrm{m}_{0}}{\mathrm{~m}_{\mathrm{p}}}=\left(\frac{1-\lambda}{\mathrm{P}-\lambda}\right) \\
\mathrm{P}=\exp \left(\frac{-\mathrm{V}+\mathrm{gt}_{\mathrm{f}}}{\mathrm{u}}\right)
\end{gathered}
$$

If we set $\mathrm{V}=7.6 \mathrm{~m} \mathrm{~s}, \mathrm{u}=3 \mathrm{~km} \mathrm{~s}^{-1}, \lambda=0.1, \mathrm{~g}$ $=9.8 \mathrm{~m} \mathrm{~s}, \mathrm{t}=350 \mathrm{sec}$ then we have;

$$
\begin{aligned}
& P=\exp \left(\frac{-7600+(9.8 \times 350)}{3000}\right) \\
& =\exp \left(\frac{-7600+3430}{3000}\right)=\exp (-3.67) \mathrm{P}=0.025
\end{aligned}
$$

Hence,

$$
\begin{gathered}
\frac{\mathrm{m}_{0}}{\mathrm{~m}_{\mathrm{p}}}=\frac{1-0.1}{0.025-0.1}=\frac{0.9}{-0.074} \\
\frac{\mathrm{m}_{\mathrm{o}}}{\mathrm{m}_{\mathrm{p}}}=-12.162
\end{gathered}
$$

For $\mathrm{n}=2$,

$$
\begin{gathered}
\frac{\mathrm{m}_{\mathrm{o}}}{\mathrm{m}_{\mathrm{p}}}=\left(\frac{1-\lambda}{\mathrm{P}-\lambda}\right)^{2}, \mathrm{P}=\left(\frac{-\mathrm{V}+\mathrm{gt}_{\mathrm{f}}}{2 \mathrm{u}}\right) \\
\mathrm{P}=\exp \left(\frac{-7600+(9.8 \times 350)}{2 \times 5000}\right)=\exp \left(\frac{-7600+3430}{6000}\right) \\
P=\exp (-1.84)=0.159
\end{gathered}
$$

Table 1: Values of the mass

\begin{tabular}{lc}
\hline $\mathrm{n}=$ no of stages & Mass (ton) \\
\hline 1 & 232 \\
2 & 100 \\
3 & 82 \\
4 & 75 \\
5 & 60 \\
$\infty$
\end{tabular}

$$
\frac{\mathrm{m}_{0}}{\mathrm{~m}_{\mathrm{p}}}=\left(\frac{1-0.1}{0.159-0}\right)^{2}=(15.25)^{2}
$$$$
\frac{m_{0}}{m_{p}}=233
$$

$$
\mathrm{n}=3, \frac{\mathrm{m}_{0}}{\mathrm{~m}_{\mathrm{p}}}=\left(\frac{1-\lambda}{\mathrm{P}-\lambda}\right)^{3}, \mathrm{P}=\exp \left(\frac{-\mathrm{V}+\mathrm{gt}_{\mathrm{f}}}{3 \mathrm{u}}\right)
$$

$$
\begin{aligned}
& \mathrm{P}=\exp \left(\frac{-7600+(9.8 \times 350)}{3 \times 3000}\right)=\exp \left(\frac{-7600+3430}{9000}\right) \\
& =\exp (1-1.225)=\frac{\mathrm{m}_{0}}{\mathrm{~m}_{\mathrm{p}}}=\left(\frac{1-0.1}{0.29-0.1}\right)^{3}=101
\end{aligned}
$$

It can be shown for $\mathrm{n}=4, \mathrm{~m}=5$ that $\mathrm{m}_{\mathrm{o}} / \mathrm{m}_{\mathrm{p}}$ are 82 and 75 , respectively and for $\mathrm{n}=\infty, \mathrm{m}_{\mathrm{o}} / \mathrm{m}_{\mathrm{p}}=60$;

$$
\begin{aligned}
& \frac{\mathrm{m}_{\mathrm{o}}}{\mathrm{m}_{\mathrm{p}}}=\exp \left(\frac{\mathrm{V}+\mathrm{gt}_{\mathrm{f}}}{(1-\lambda) \mathrm{u}}\right)=\exp \left(\frac{7600+9 \times 350}{(1-0.1) \times 3000}\right) \\
& =\exp \left(\frac{760+3430}{2700}\right)=\exp \left(\frac{11,030}{2700}\right)=\exp (4.85)=60
\end{aligned}
$$

Values of the mass of an n-stage rocket to orbit, a 1 ton satellite for $\mathrm{v}, \mathrm{u}$ and $\lambda$ assumed before is shown in Table 1.

From Table 1, it is almost impossible to use a onestage rocket to put a satellite in orbit as the engine has to accelerate the whole dead weight of the structure up to the final velocity, thus the poor performance. When the fuel is almost exhausted, the engine is using most of its effort in accelerating an almost empty tank and payload.

The mass of a 2-stage rocket is greater than that of the 3-stage rocket. The more massive an object, the greater is the gravitational pull experienced. The gravitational pull impedes the rocket motion thus reducing the final velocity.

It is nice and worthwhile to use the 3-stage instead of 2 because of the weight reduction. In real sense, the weight reduction obtained by using 4-stage instead of three is nullified by the complexity and experience of making an extra engine. 


\section{CONCLUSION}

The researchers have been able to provide a mathematical formulation for the model of an n-stage rocket to put a satellite in orbit considering the effect of gravity. It is quite evident that a higher escape velocity can be achieved with a 3-stage rocket because of the weight reduction from the discussion. Also energy is not expended accelerating empty fuel tanks and is the case for a 1 -stage rocket. Since each tank is discharged. It is also worth noting that the 3-stage rocket is cost effective compared with the 4-stage which also gives a reduction in weight. In this study, the analysis shows that the 3 -stage rocket gives the optimum stage for a rocket mission.

\section{REFERENCES}

Ball, K.J. and G.F. Osborne, 1967. Space Vehicle Dynamics. Oxford University Press, London.

Hill, P.G. and C.R. Perterson, 1990. Mechanics and Thermodynamics of Propulsion. Addisson-Wesley Publishing, USA.

Larson, W.J. and J.R. Wertz, 1992. Space Mission Analysis and Design. Klumer Academic Publishers, Boston MA., pp: 871.

Sutton, G.P., 1986. Rocket Propulsion Elements. John Wiley, New York, pp: 768-768.

Young, H.D. and A. Roger, 1965. Mechanics and Thermodynamics of Propulsion. 9th Edn., Addisson Wesley Publishing Co., USA., pp: 358-360. 